\title{
Working
}

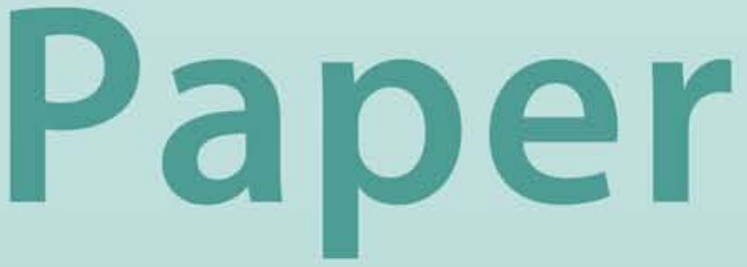




\section{An Incentive Approach to Identifying Financial System Vulnerabilities}

Jingqing Chai and R. Barry Johnston 


\title{
IMF Working Paper
}

Monetary and Exchange Affairs Department

\section{An Incentive Approach to Identifying Financial System Vulnerabilities}

\author{
Prepared by Jingqing Chai and R. Barry Johnston ${ }^{1}$
}

December 2000

\begin{abstract}
The views expressed in this Working Paper are those of the author(s) and do not necessarily represent those of the IMF or IMF policy. Working Papers describe research in progress by the author(s) and are published to elicit comments and to further debate.
\end{abstract}

This paper underscores the importance of the assessment of incentives of the main agents in a financial system as a key element in the analysis of financial system vulnerability and the surveillance over the financial system. We outline a diagnostic approach for the assessment of incentives. This approach highlights the need for additional research on the relationship between institutional structures and financial vulnerabilities.

JEL Classification Numbers: B4, G15; G38

Keywords: asymmetric information, market structure, incentive assessments

Author’s E-Mail Address:jchai@imf.org; bjohnston@imf.org

\footnotetext{
${ }^{1}$ The authors would like to express their appreciation to participants in divisional and departmental seminars who commented on an earlier draft of this paper and to Masayuki Tamagawa for his comments on the illustrative example.
} 


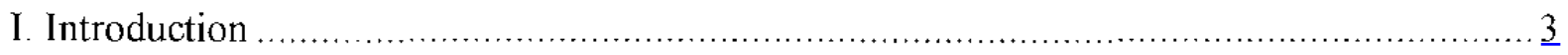

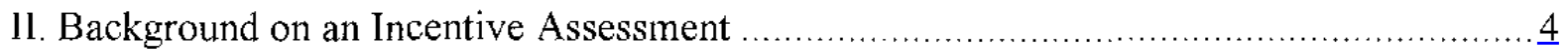

III. Framework for Examining Incentives in the Financial System ........................... $\underline{6}$

A. Key Elements in a Financial Environment .............................................. 9

Market structure and financial instruments (MFI) .............................. $\underline{9}$

Government safety net (GSN) ................................................ 10

Legal framework and quality of enforcement (LFE) ...................... 10

B. Taxonomy of Financial Systems ............................................................. 11

C. Prioritizing the Investigation of Incentives ........................................ 12

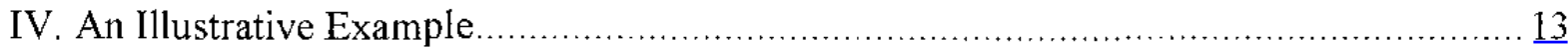

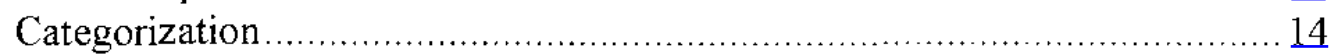

Prioritizing the questions under Category (3) ................................... 15

Conclusion ........................................................................

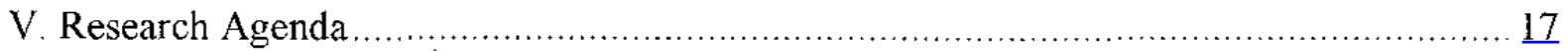

Figures

1. Three Key Elements in a Financial Environment …...................................... I

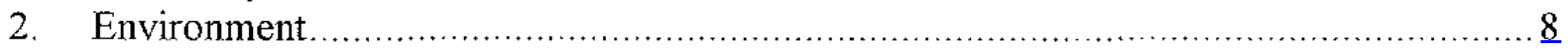




\section{INTRODUCTION}

This paper discusses the role of an examination of incentives in identifying potential vulnerabilities that could result in instability in a financial system. While economic analysis has emphasized the critical importance of incentives in determining behavior, the assessments of financial systems and the adequacy of financial regulations have not so far taken account of incentive structures in any systematic way. ${ }^{2}$ We argue in this paper that an approach that focuses on the assessment of incentives of the main agents in a financial system should be one of the key elements in the analysis of financial system vulnerabilities and the surveillance over financial systems. We outline a diagnostic approach similar to that employed in many other branches of scientific investigation, such an approach highlights the need for additional research on the relationship between institutional structures and financial vulnerabilities.

A key economic concept underlying the incentive approach is asymmetric information (AI): a situation in which one party to a financial transaction has superior information to another. While financial intermediaries arise as a particular solution to the problems of $\mathrm{AI}$, AI remains a crucial impediment to the effective functioning of a financial system. ${ }^{3}$ Recent experience with banking and currency crises has underlined, for example, the role of moral hazard in reducing incentives to monitor performance, and the problems of adverse selection and herding behavior in creating vulnerabilities in financial systems. ${ }^{4}$ The other key economic concept underlying the incentive approach is market structures. A growing theoretical literature has focused on the relationship between financial market structures and economic behavior, which is shown to potentially give rise to certain vulnerabilities for a financial system. ${ }^{5}$

The incentive approach recognizes that certain combinations of key structural and policy elements may aggravate the incentive problems to the extent of destabilizing a financial system. In this paper, we identify the three key structural and policy elements in a given environment that have been shown to affect the incentives of the main agents in the financial system operating within that environment: that is the market structure, the existence of government safety nets and the legal and regulatory framework. The paper then goes on to examine how the environment within which financial transactions take place affects the risk

${ }^{2}$ See Johnston, Chai and Schumacher (2000) for a review of the methodologies used to assess financial system vulnerabilities.

${ }^{3}$ Mishkin (1996) discussed the role of asymmetric information in banking and financial crises.

${ }^{4}$ Diamond and Dybvig (1983) is an early example of this work.

${ }^{5}$ See for example the discussion on the effects of banking concentration on moral hazard in risk taking as well as on the risk of contagion (Johnston, Chai and Schumacher (2000)). 
taking, hedging and monitoring behavior of the main agents in the "core" of a financial system-investors, borrowers, intermediaries - as well as the incentives of the regulators, supervisors and markets to monitor and regulate risk taking behavior. The balance of these factors determines the resulting net risk taking behavior or vulnerabilities in the financial system.

By focusing directly on the factors that influence economic behavior, this approach differs in scope and philosophy from the other two main techniques that have been used in assessing financial vulnerabilities-statistical based assessments (quantitative analysis without behavioral references) and the review of compliance with codes and standards in the financial system (one-size-fits-all snap shots). The focus on economic incentives of the main agents can accommodate great diversity in the organization of financial systems, and go beyond relying on quantitative or regulatory benchmarks (such as regulatory standards) to assess vulnerabilities in financial systems. In addition, since we already know about some of the potential risks from various asymmetric information problems, incentive issues, once identified, can provide earlier detection of potential financial problems than assessments based on prudential indicators, which are generally effective after the financial problems materialize. Theoretical and empirical understanding of the role of incentives in the operation of financial systems form the basis for the criteria that will be used to make the incentive assessments. This implies that the type of information that would need to be sought in assessing financial system vulnerabilities would be somewhat different from that used for statistical based assessments and reviews of codes and standards.

This paper is organized as follows: Section Il discusses background to the concept of an incentive assessment; Section III outlines the general framework for conducting an incentive assessment and discusses the key structural and policy elements that can influence incentives; Section IV illustrates the role of such an incentive assessment in helping identify the sources of vulnerabilities in a country that has experienced financial problems; Section $V$ concludes with a preliminary proposal for a research agenda that will help facilitate the incorporation of incentive assessment into financial system stability assessments.

\section{BACKGROUND ON AN INCENTIVE ASSESSMENT}

The rational for an incentive assessment derives from the economic literature on financial intermediation. This literature provides a framework for classifying and analyzing the fundamental nature of financial systems, based on the incentives faced by the various participants. It is well recognized in this literature that certain types of incentives result in vulnerabilities in financial systems and unsound banking practices.

Asymmetric information is a potential source of fundamental weakness in financial systems because it leads to problems of adverse selection and moral hazard:

- Adverse selection occurs when agents with the greatest potential risks are more likely to enter into arrangements that reduce their risk. 
- Moral hazard arises when agents do not bear the full costs or benefits of their actions and thus have the incentive to assume additional risk.

Additionally, problems of adverse selection and moral hazard can take the forms of free-rider problems, principal-agent and monitoring problems, rational herding and contagion:

- Free-rider problems arise where an agent that collects information about a particular risk is unable to prevent other agents from using that information, and is thus unable to appropriate the full benefits of collecting the information.

- Principal-agent and monitoring problems arise where a principal cannot observe perfectly the actions of the agent to whom the principal delegates a certain activity or responsibility.

- Rational herding occurs for example where (a) the payoffs to an agent adopting an action increases with the number of agents adopting the same action (payoff externalities); (b) when markets are imperfectly informed, agents may prefer to "hide in the herd" or "ride the herd" as a risk averse strategy to maintain relatives returns; and (c) agents gain useful information from observing previous agents' decisions to the point where they optimally and rationally completely ignore their own private information (information externalities or cascades).

- Contagion occurs for example where a shock in one asset market affects prices in other asset markets. This because investors are not all informed about the risks, and, thus cannot distinguish cross-market hedging from information-motivated sales.

The above factors can influence the behavior of a variety of agents in the financial system, including the intermediaries, the borrowers, the investors and the supervisors and regulators. A typical discussion of the impact of unsound banks on the volume and efficiency of intermediation highlights the problems of adverse selection and moral hazard. A bank facing insolvency may lend to existing unprofitable or insolvent customers to prevent defaults that would in turn result in open insolvency of the bank; the insolvent bank may lend to new high risk borrowers in an effort to "gamble for resurrection"; the insolvent bank may also increase lending to interrelated entities as a way for the owners to extract further equity from the bank.

The effects of implicit and explicit government exchange rate and deposit and loan guarantes in creating problems of moral hazard for international investors and domestic borrowers have been highlighted by the Asian currency and banking crises. Implicit and explicit exchange rate guarantees contributed to large short-term capital inflows and over investment due to an underestimation of the exchange rate risks involved in the Asian currency crisis economies (Korea, Indonesia, Thailand). In addition the severity of the crisis was compounded by herding behavior among international investors in advance of the crisis and contagion when the crisis first occurred. 
Experiences with handling distress in banking systems have highlighted potential issues of moral hazard among the supervisors and regulators when there has been a tendency to regulatory forbearance rather than intervention to deal with banking problems because of the lack of independence of the regulatory agency. Poorly designed crisis management systems and procedures for closing banks have also given rise to risks of systemic vulnerability due to the risks of contagion.

Financial crises have also been traced to principal agent and monitoring problems that are manifest in ownership structures and corporate-governance. In general, ownership structures and corporate governance can affect the incentives of managers to assume risks and owners to monitor risk taking. Interrelated ownership of financial and non financial corporations has been an important source of financial sector vulnerability, especially where the incentives of other creditors to monitor performance have been weak, due for example to the expectation of official bail outs.

Finally, policy and financial innovations, for example those associated with financial liberalization, have aggravated the problems of moral hazard and adverse selection, especially when the innovations led to changes in banking structure, erosion in franchise values in certain markets and where market participants and regulators were not yet attuned to assessing risks in this new environment. Excessive risk-taking and insufficiently monitored financial risks have been the main reasons for banking problems following liberalizations in several countries.

\section{FRAMEWORK FOR EXAMINING INCENTIVES IN THE FINANCIAL SYSTEM}

Incentives in the financial system are influenced both by the environment under which financial agents operate and the interrelationships between the main participants in the financial system (Figure 1). In an effort to make this distinction more tractable, we first identify the three key elements that can characterize the environment under which financial transactions are undertaken: (1) market structure and the availability of financial instruments; (2) government safety nets; and (3) the legal and regulatory framework. We then aim to categorize a financial system (i.e., provide a taxonomy) based on whether those elements play a major role in that system. Given the taxonomy, an incentive assessment would identify and prioritize a set of questions in order to ascertain the effects of these elements on the incentive structure of the main agents within the core of the financial system that are most likely to cause financial vulnerabilities. The incentive assessment would take the form of a pyramid of flow charts consisting of answers to questions about the factors that influence the incentives of the key players (Figure 2). The first level of questions would quantify the environment within which agents operate. The second level of questions would identify specific issues to be assessed under each environment. The categorization of an environment and the prioritization of the next-level questions constitute a "trial-and-error" diagnostic process. Finally, corresponding questions are asked to determine whether there are sufficient checks and balances to the moral hazard and adverse selection problems identified. 
Figure 1. Three Key Elements in a Financial Environment

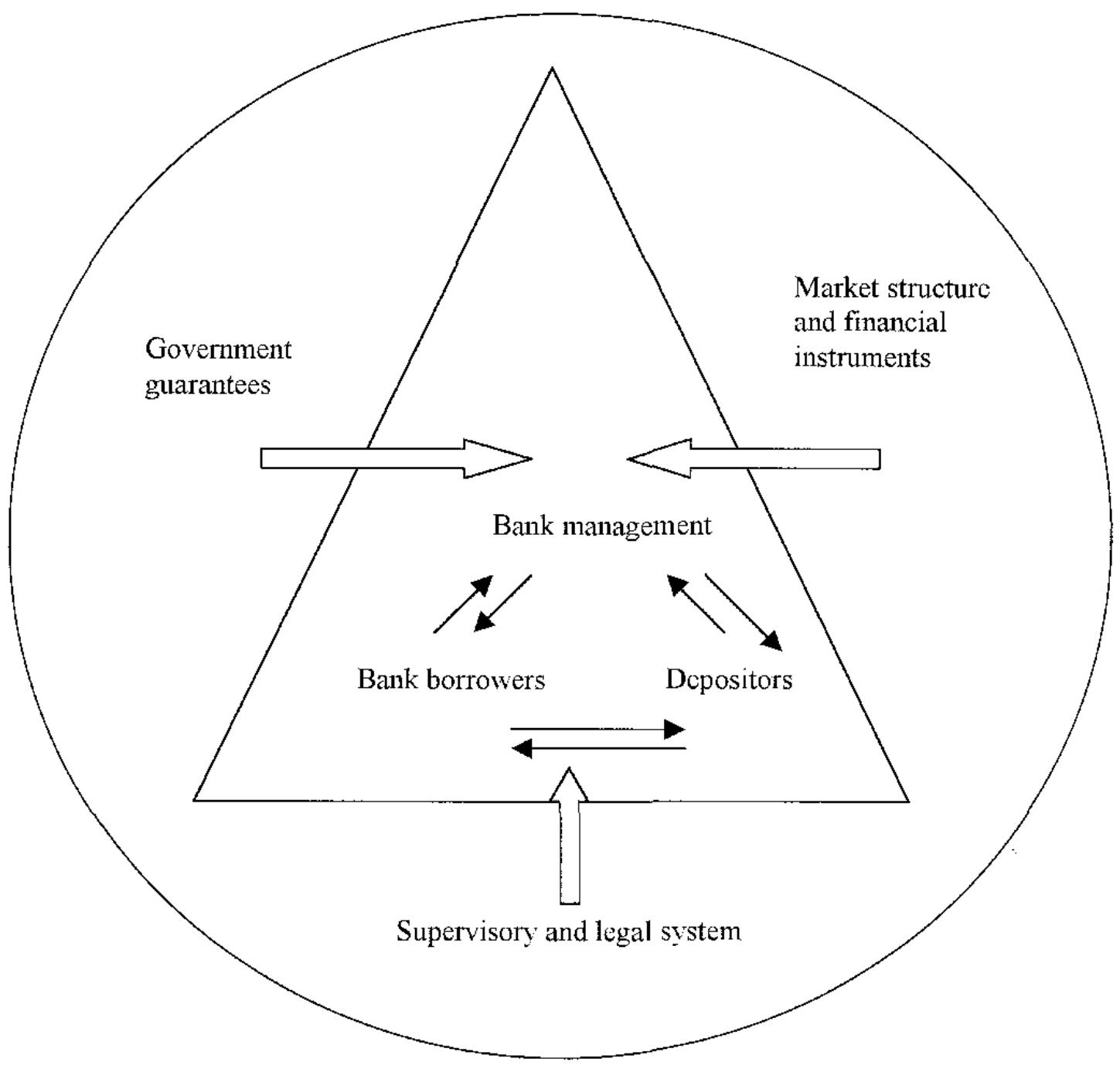


Figure 2. Environment

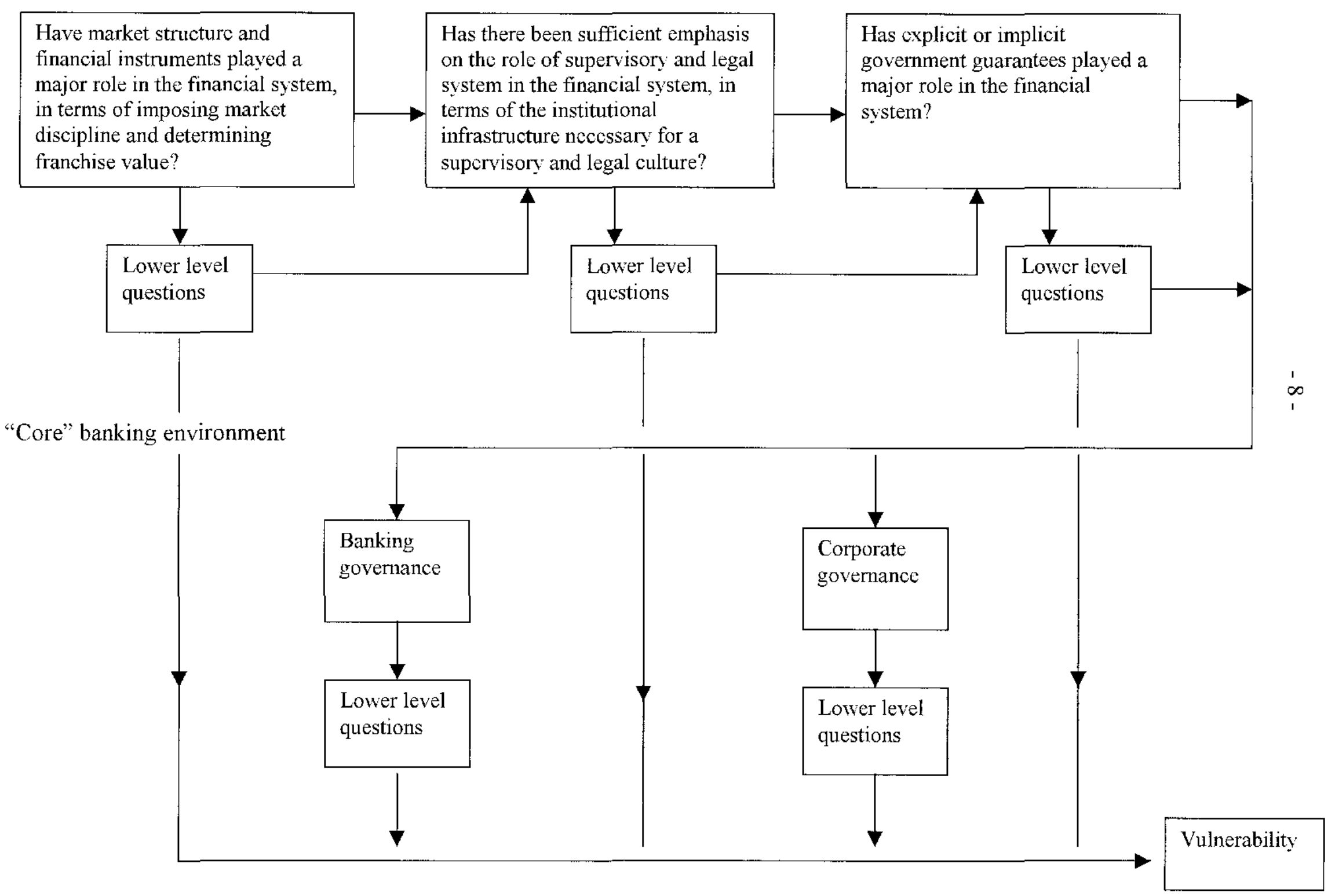




\section{A. Key Elements in a Financial Environment}

A financial system is conditioned by the external environment in which the system operates. We describe the external environment of a particular financial system by focusing on three key elements that influence incentives in the financial system: the market structure and financial instruments; the existence or otherwise of official guarantees and safety nets; and the legal and regulatory framework.

\section{Market structure and financial instruments (MFI)}

Market structure and the availability of, or lack thereof, competing financial instruments (MFI) are fundamental issues in determining the incentives confronting agents in the economy. They affect the incentive structure of depositors and borrowers and the banks and non-bank financial intermediaries in a number of ways.

First and foremost, the availability of competing financial instruments is a necessary condition for market discipline. Whether it is sufficient or not will depend on a number of additional factors (such as the adequacy and transparency of information) which we consider part of infrastructure of the "core" environment. At one end of the spectrum, many of the developed countries have sophisticated financial systems where market discipline plays a major role and helps to mitigate moral hazard and adverse selection facilitated by the highly developed debt and equity markets and good accounting and information systems. In developing countries, however, market discipline plays a minor role where there are few options for households, and corporations in borrowing and allocating their wealth. Among the least sophisticated financial systems, state-owned bank still play an important role in the allocation of credit, limiting the role of competition.

However, a more competitive market structure may also result in financial vulnerabilities. For example, more competitive financial systems may reduce the franchise value of the banks and thus increase the incentives for managers working on behalf of shareholders to take on more risks at the expense of debt holders and depositors. ${ }^{6}$ In addition, when a greater degree of availability of financial instruments gives the non-financial corporate sector access to alternative external sources of financing, the adverse selection problem in corporate financial markets may worsen banks' balance sheets and reduce franchise value.

A number of elements would need to enter into an assessment of MFl, including the external environment, the role of subordinated debt, the olygopolistic nature of the banking system. For example, the openness of the capital market (de facto or de jure) can be an important source of competition.

${ }^{6}$ See for example Allen and Gale (1999). 


\section{Government safety net (GSN)}

A form of GSN that is shown to have caused financial instability is explicit or implicit exchange rate guarantees. Experience from a number of countries has concluded that such guarantees can result in large short-term capital flows in the case of exchange rates targets and inconsistency between the exchange rate and interest rates, and when capital account is sufficiently liberalized. ${ }^{7}$ Large capital flow reversals have resulted when the exchange rate guarantees were no longer viewed as sustainable. The resulting currency crises more often than not led to banking crises because banks suffered losses from large open currency positions or loan losses from exposed borrowers.

Deposit insurance or guarantees, often adopted as a response to the potential threat of bank runs caused by $\mathrm{AI}$ on the part of un-informed depositors, may generate additional problems of moral hazard and adverse selection, especially when deposit insurance schemes are ill designed. Banks are more likely to take excessive risks in the absence of depositor discipline but features such as sensitivity of pricing insurance premiums to the riskiness of portfolios and effective monitoring by this deposit insurance agency can help mitigate these risks.

Similar moral hazard problem may arise when depositors, other creditors, or supervisors perceive that implicit or explicit government guarantees are granted to banks and/or corporate borrowers in the form of credit line or bailout. Such perceptions not only tend to reduce monitoring efforts on the part of the creditors and supervisors but also give incentives to banks to take excess risks in lending.

\section{Legal framework and quality of enforcement (LFE)}

A complete legal framework and high quality of enforcement are essential for disciplining the behavior of banks and firms through safeguarding property rights and providing investor protection against expropriation by insiders. For the same reason, countries with relatively complete legal framework and high quality of enforcement tend to have more developed capital markets, which facilitate banks and corporate borrowers in raising external financing.

The effectiveness of a legal framework depends not only on the quality of the laws and regulations but also the quality of implementation. The quality of enforcement crucially depends on the underlying strength and integrity of public officials and institutions that are

\footnotetext{
${ }^{7}$ Greater freedom of capital movements implies that short-term interest rates in domestic markets will increasingly be determined by the covered interest rate condition, and attempts to set both interest rate and exchange rates inconsistent with this condition is likely to lead to short-term capital flows as markets respond to the incentives created to switch investments between countries.
} 
themselves affected by the incentives and traditions in the economy. Weakness in the court system has led to long delays in legal decision on cases involving bankruptcy or bank resolution/liquidation. Weakness in supervisory institutions reduces the effectiveness of laws related to depositors and banking institutions. A country with a relatively complete legal framework may have underdeveloped or weakened supervisory institutions. Lack of supervisory independence may interfere with the supervisory institutions capacity or incentives to carry out their duty of monitoring and disciplining banks for moral hazard and adverse selection problems. A government that is prone to corruption may lead to bad public policies that give banks and borrowers wrong incentives.

\section{B. Taxonomy of Financial Systems}

We can use the above three characteristics of the environment-MFI, LFE and GSN-to develop a taxonomy of financial systems. While there are eight possible combinations of the three environments, in practice most financial systems would seem to fall into the following four categories. Financial systems where:

(1) MFI, LFE, and GSN all play a major role. Most advanced financial systems would fall into this category with varying degree of importance of GSN;

(2) Only MFI plays a major role, and where LFE or GSN are not well developed. Some newly liberalized financial systems in transition economies, such as the former Soviet Union countries, and poorer countries liberalizing financial systems that lack the financial resources to provide credible government guarantees would seem to fall into this category;

(3) Only MFI and GSN play a major role, with a lack of LFE. Liberalizing financial systems with continued extensive government involvement, but weak legal and regulatory systems, such as found in Asia prior to the currency crises would fall under this category; and

(4) Only GSN plays a major role, with a lack of MFI and LFE. This category would relate especially to economies that have not yet liberalized their financial systems, and continue to rely to a large extent on government owned institutions and direct instruments.

For the purposes of conducting an incentive assessment, indicators would need to be developed as a basis to characterize the existence of MFI, GSN, and LFE. Here, it is important that the indicators do not include or exclude a certain characteristic when its presence or absence plays an important role in that system. Instead, where the initial assessment is uncertain, the assessment should proceed to the next-level questions. In short, these initial assessments should err on the side of caution.

Given such a diagnostic approach, a set of variables may be identified, from which it would be possible to infer whether MFI, LFE, or GSN plays a major role (that is, they take 
the value of 1) in a particular financial system. For example, the following indicators illustrate the type of indicators that could be used:

- $\quad$ MFI equals I if average household holdings of non-bank-deposit financial assets exceed a certain margin or bonds or securities markets expand at a certain rate, and 0 otherwise.

- $\quad$ LFE equals 1 if there has been at least one case each of corporate bankruptcy and bank closures in the past five non-crisis years, and 0 otherwise.

- GSN equals 1 if there is an implicit or explicit exchange rate target or deposit insurance guarantee in place or if there has been no corporate bankruptcy or bank closures/restructuring in any of the past five non-crisis years, and 0 otherwise.

Identification of the appropriate indicators would be a matter for research and of experience in conducting financial sector vulnerability assessments. It seems likely, however, that the information that would need to be developed to make these assessments would be somewhat different from that collected for statistical based assessments and reviews of codes and standards, and would focus to a greater extend on institutional capacity, legal and regulatory enforcement, and governance aspects of the financial system, as well as the external environment.

\section{Prioritizing the Investigation of Incentives}

Once we decide whether certain environmental elements play a major role in a financial system, the next step in the evaluation of financial vulnerabilities would be to prioritize the assessment of incentives mindful of the likely effect of the environment on the likely behavior of the main agents in the financial system. Here the literature on banking and corporate governance may play a useful role in helping to identify AI and other issues that are prone to cause financial instabilities.

Questions to be prioritized under each category are illustrated as follows:

Category (I)-MFI, LFE, and GSN play a major role in influencing the functioning of the financial system

Questions concerning accounting standards and disclosure practices in order to ascertain the degree of market discipline imposed by competing financial instruments as well as the effect of market structure on banks' franchise value;

Questions concerning legal rules for investor protection and the quality of enforcement to determine the degree of external discipline on the behavior of bank or corporate management; and 
Questions concerning supervisory controls to determine whether they are sufficient for mitigating moral hazard and adverse selection that may result from government safety net.

The answers to the above questions will help to determine whether the incentives of banks and their borrowers are likely to be properly aligned with the level of risk. If the answers to these questions suggest that there is inadequate control on risks involved, then it would be appropriate to move on to the next level of questions addressing the internal governance of a bank and its major corporate borrowers. The answers to these questions would provide the basis for the assessment of whether risk management systems are commensurate with the risk-taking involvement

\section{Category (2)--Only MFI plays a major role, lack of $L F E$ or $G S N$}

Questions should focus on accounting standards and disclosure practices to ascertain the degree of market discipline. In the absence of good disclosure and accounting standards, question would focus on supervisory controls for mitigating moral hazard and adverse selection in banking. If the answers suggest that the incentives of banks and their borrowers are not properly aligned with the level of risk that is appropriate for the system, questions addressing the internal governance of the banks and corporate borrowers are needed.

Category (3)-Only MFI and GSN play a major role, lack of LFE

Questions should be focused on accounting standards and disclosure practices as well as supervisory controls. However, in the absence of the check and balances from the enforcement of supervisory and legal system, internal governance of a bank and its major corporate borrowers is likely to be critically important for the stability of the financial system. It is notable that prior to the Asian crisis, a good deal of surveillance focused on the legal and regulatory framework and much less on the role of governance and enforcement of laws and regulations. Weaknesses in these factors were important contributors to the Asian crisis.

Category (4) - Only GSN plays a major role, lack of MFI and LFE

The incentives of state-owned banks under explicit or implicit government guarantees are crucial for assessing the vulnerabilities of the financial system, partly because there is no role for market discipline without the availability of competing financial assets or foreign assets, and the development of property rights is marginalized in the environment of state planning.

\section{AN ILLUSTRATIVE EXAMPLE}

Below we apply the above approach to show how the categorization of the changing environment in Japan and the prioritization of questions on the incentives of the corporate and banking sectors may help identify the aspects of their incentive structures that may have 
given rise to Japanese banking system's financial problems that emerged in early $1990 \mathrm{~s} .{ }^{8}$ The purpose of this exercise is not to explain, with the benefit of the hindsight, the structural causes of Japan's banking problems, but rather to illustrate the incentive problems that could potentially lead to banking problems, especially when there is a persistent downward shock to the economy that exposes vulnerabilities..

\section{Categorization}

\section{Development of the securities markets and resulted changes in banking structure}

The external environment for the Japanese banking system has undergone significant changes from the mid-1970s. Initially, borrowed capital gave way to internally generated funding as a major source of finance among larger firms. Then, during the $1980 \mathrm{~s}$, the declining dependence of major corporations on bank loans accelerated, as the deregulation of securities markets facilitated bond and to a larger extent equity-related finance. Several macroeconomic developments contributed to the development of the securities markets, including the strength of the yen as an international currency and the favorable economic outlook that gave rise to bullish equity valuation and a boosted demand for foreign and domestic issues in yen of bonds and equity-related debt.

Initial assessment: MFI may play an important role in shaping the incentives of corporate borrowers and banks.

\section{Government safety nets}

The Japanese banking industry was subject to latent moral hazards related to the financial safety nets. Between the end of the Second World War and 1996, no bank had been allowed to fail. This may be interpreted as a form of implicit protection offered to shareholders in banks. There may also potentially be problems associated with the protection offered to the depositors of banks. Between 1971 and 1996, the banks were charged deposit insurance premia at a flat rate of 0.012 per cent of deposit liabilities. However, investigations involving the next level questions are needed in order to ascertain whether the observation of no formal bank failure and the insensitivity of deposit insurance premium to risk may have led to moral hazard in the lending behavior of the banks.

Initial assessment: GSN may play an important role in shaping the incentives of banks and depositors.

\footnotetext{
${ }^{8}$ We draw some empirical evidence from Gower (May 2000).
} 


\section{Legal framework and quality of enforcement}

Although Japan has a culture based on order and a relatively complete legal framework, a number of issues with the regulatory infrastructure emerged in the early $1990 \mathrm{~s}$, leading to regulatory forbearance. Since the 1970 s, Japan adopted a regulatory philosophy that relied on private arrangements through purchase-with-assumptions or other marketbased mechanisms to deal with problematic banks rather than resulting to formal legal actions. While this differs from the formal prompt action corrective system used in other industrial countries, this regulatory philosophy appears to have served the Japanese banking system well during the boom period of 1980 s. Indeed, at that time, economic conditions were so favorable and banking practices were so lucrative that not one bank identified by the Japanese supervisory authority as problematic failed to find other banks that were willing to purchase or merge with it on the basis of the positive evaluation of its franchise value. Consistent with this philosophy, there were no clear regulatory procedures for formal resolution of failing or insolvent banks.

Initial assessment: LFE may play a minor role in providing prudential oversight over banks.

\section{Prioritizing the questions under Category (3)}

As discussed above, questions should be focused on accounting standards and disclosure practices as well as supervisory controls. In addition, because government safety nets may play an important role, questions on the internal governance of banks and the behavior of their major corporate borrowers are also important.

Questions on supervisory and judicial processes reveal that:

Several features of the Japanese supervisory framework led to weakened prudential oversight as an increasing number of banks started to experience financial problems at the onset of the economic downturn. First, the Japanese accounting practices did not support mark-to market valuation. While this might not have been a problem during an economic boom with rising asset prices, it allowed banks to conceal their problems loans and possibly circumvent regulatory oversight when the asset prices started to fall. Second, during the boom, banking supervision was viewed as adequate, and the prudential requirement of riskweighted capital adequacy was not considered necessary. However, as the economic downturn started to take hold in early $1990 \mathrm{~s}$, the supervisory authorities were slow to strengthen their oversight of certain activities that were shown to be higher risk by the large volatilities in asset prices. Third, as mentioned above, since there were no clear regulatory procedures for formal resolution of failing or insolvent banks, the supervisory authorities were not able to resort to judicial process to deal with failing banks, when the magnitude of the financial problems facing a sizeable number of banks made solutions based on private arrangements increasingly difficult. This lack of options for the supervisory authorities in effectively dealing with failing banks may have to some extent led to regulatory 
forbearance. ${ }^{9}$ Finally, insufficient supervision of the activities of the non-bank financial affiliates of major banks also led supervisors to underestimate the problems facing those banks.

Questions on banks' lending behavior indicate that:

As discussed above, banks were losing high-quality and often long-term borrowers to corporate bond and equity markets throughout the 1980s. This change in the banking structure and attendant erosion in the franchise value of bank core operations led banks actively to seek out lending opportunities to other sectors, mainly real estate, that were unfamiliar but offered higher nominal rates of return. Again, the favorable economic outlook in the midst of the longest economic boom in Japan's history led banks to underestimate the potential downside risks associated with this type of new lending. More importantly, the first signs of potentially riskier nature of such lending, as shown by the volatilities in asset prices in early $1990 \mathrm{~s}$, were not accounted for by banks risk management systems leading to a deterioration in the quality and profitability of banks' portfolio. In the meantime, banks were pressured from the enhanced competitions into reducing margins to the point of reducing monitoring and screening.

Questions on the managerial incentives in risk-taking and monitoring suggest that:

As noted, an alternative to formal liquidation, troubled financial institutions were merged with more stable banks. These mergers were often on terms that respected the interests of shareholders in the troubled institution (Aoki et al 1994). This might have made the banks vulnerable to managerial slack; at worst, it may have encouraged individual bank managers to seek out projects with a high-risk/high-return profile, when franchise values were threatened.

Questions on the behavior of depositors suggest that:

Insensitivity of deposit insurance's pricing arrangement to the riskiness of portfolios may have been one of the contributing factors to banks' continuing to lend to sectors that they recognized as high risks in the early 1990s. While banks were increasingly targeting high risk borrowers and monitoring their clients less effectively, households continued to hold their savings as bank deposits because they believed, with some justification, that those savings were subject to implicit guarantees. While these two factors may have played a minor role in influencing the behavior of the banks during the economic boom, they may have become an important contributing factor to banks' prolonging their financial problems and worsening the magnitude of the problems when economic conditions started to deteriorate in the early $1990 \mathrm{~s}$.

${ }^{9}$ The literature on the structural causes of the Japanese banking problems has also cited political influences exerted on supervisors to allow failing banks to stay in business. 


\section{Conclusion}

Three sources of potential vulnerabilities in the banking sector emerge from the above exercise. ${ }^{10}$ First, the deterioration in the quality of the banks' loan portfolios developed in the early 1990 s as a result of the increasing access to external financing (mainly through equity market by Japanese corporations) and the subsequent adverse selection problem in the Japanese bank lending market, specifically when the riskier nature of real estate lending was not accounted for by banks. Second, given the various safety nets in operation in Japan at the time, there was no effective monitoring of banks' behavior by depositors. Third, features of the supervisory system and accounting practices weakened the disciplining and monitoring by supervisors and markets.

In this particular example, the timing of the incentive assessments is relevant. When Japan was in the long period of an economic boom, many would argue that excessive risk taking was not an issue--on the contrary, banks were perceived to be cautious and innovative in seeking out new, potentially profitable sectors. Incentive assessments conducted within this period may not be able to identify incentive problems, since the incentive of the agents were probably aligned with the perceived risks. However, when the riskier nature of such new lending manifested itself in the volatilities of the underlying asset prices, the banks continued the heavy lending to such sectors without properly adjusting for the risks. A timely incentive assessment at the onset of the economic downturn, temporary or permanent, could reveal a combination of moral hazard and adverse selection problems that could potentially cause financial vulnerabilities - in the case of Japan they did lead to serious financial problems facing the banking system.

\section{RESEARCH AGENDA}

The above approach highlights the need for additional theoretical and empirical research on the relationship between institutional structures and financial vulnerabilities. This research focus helps deepen the understanding of how institutional structures affect incentives structure in ways that make a system prone to financial instability. Results and findings from this research can help develop the criteria for making incentive assessments.

Two sets of questions are important for applying the above framework. One is on the quantification of the taxonomy in order to categorize countries and thereby prioritize information collection on the next-level questions. Research can be built on the existing empirical and theoretical literature on legal systems, the different nature of government guarantees, and the effects of market structures.

The second set of questions concern banking and corporate governance, especially how the environment within which financial transactions take place affects the risk taking,

\footnotetext{
${ }^{10}$ This conclusion concurs with some of the corporate finance literature that explain structural causes of Japan's banking problems.
} 
hedging and monitoring behavior of the main agents in the "core" of a financial systeminvestors, borrowers, intermediaries - as well as the incentives of the regulators and supervisors to monitor and regulate risk taking behavior, and the implications of the resulting net risk taking behavior for vulnerabilities in the financial system. Research on theoretical and empirical understanding of the operation of banks, corporate borrowers, and supervisors will help pinpoint the questions to be asked at the second-level. 


\section{References}

Allen, F. and D. Gale, 1999, Comparing Financial Systems, (Cambridge, Massachusetts: MIT Press).

Aoki, M and H. Patrick (1994), The Japanese Main Bank System: Its Relevance for Developing and Transforming Economies, Oxford University Press, Oxford

Diamond, Douglas, and Phillip Dybvig, 1993, "Bank Runs, Liquidity, and Deposit Insurance," Journal of Political Economy, Vol 91, pp. 401-419.

Gower, Luke, 2000, "Some Structural Causes of Japan's Banking Problems," Research Discussion Paper, 2000-03, Reserve Bank of Australia.

Mishkin, Frederic, "Understanding Financial Crises: A Developing Country Perspective," NBER Working Paper, 5600.

Johnston, Chai, and Schumacher, 2000, "Assessing Financial System Vulnerabilities," IMF Working Paper, 76. 